\title{
Integration of Gender-Affirming Primary Care and Peer Navigation With HIV Prevention and Treatment Services to Improve the Health of Transgender Women: Protocol for a Prospective Longitudinal Cohort Study
}

Javier R Lama ${ }^{1}$, MD, MPH; Kenneth H Mayer ${ }^{2}$, MD; Amaya G Perez-Brumer ${ }^{3}$, MSc, PhD; Leyla Huerta ${ }^{4}$, BS; Hugo Sanchez ${ }^{4}$, BS; Jesse L Clark ${ }^{5}$, MD, MSc; Jorge Sanchez ${ }^{6}$, MD, MPH; Sari L Reisner ${ }^{2,7,8}$, ScD

${ }^{1}$ Asociacion Civil Impacta Salud y Educacion, Lima, Peru

${ }^{2}$ The Fenway Institute, Boston, MA, United States

${ }^{3}$ Department of Sociomedical Sciences, Mailman School of Public Health, Columbia University, New York, NY, United States

${ }^{4}$ Epicentro, Lima, Peru

${ }^{5}$ Department of Medicine, Geffen School of Medicine, University of California Los Angeles, Los Angeles, CA, United States

${ }^{6}$ Centro de Investigaciones Tecnologicas, Biomedicas y Medioambientales, Universidad Nacional Mayor de San Marcos, Lima, Peru

${ }^{7}$ Division of General Pediatrics, Boston Children's Hospital, Harvard Medical School, Boston, MA, United States

${ }^{8}$ Department of Epidemiology, Harvard TH Chan School of Public Health, Boston, MA, United States

\section{Corresponding Author:}

Javier R Lama, MD, MPH

Asociacion Civil Impacta Salud y Educacion

Av Almirante Miguel Grau 1010

Lima, 15063

Peru

Phone: 5112067800 ext 407

Email: jrlama@impactaperu.org

\section{Abstract}

Background: Public health strategies are urgently needed to improve HIV disparities among transgender women, including holistic intervention approaches that address those health needs prioritized by the community. Hormone therapy is the primary method by which many transgender women medically achieve gender affirmation. Peer navigation has been shown to be effective to engage and retain underserved populations living with HIV in stable primary medical care.

Objective: This study aims to assess the feasibility and acceptability of an integrated innovative HIV service delivery model designed to improve HIV prevention and care by combining gender-affirming primary care and peer navigation with HIV prevention and treatment services.

Methods: A 12-month, nonrandomized, single-arm cohort study was implemented in Lima, Peru, among adult individuals, assigned a male sex at birth, who identified themselves as transgender women, regardless of initiation or completion of medical gender affirmation, and who were unaware of their HIV serostatus or were living with HIV but not engaged in HIV treatment. HIV-negative participants received quarterly HIV testing and were offered to initiate pre-exposure prophylaxis. HIV-positive participants were offered to initiate antiretroviral treatment and underwent quarterly plasma HIV-1 RNA and peripheral CD4+ lymphocyte cell count monitoring. All participants received feminizing hormone therapy and adherence counseling and education on their use. Peer health navigation facilitated retention in care by visiting participants at home, work, or socialization venues, or by contacting them by social media and phone.

Results: Patient recruitment started in October 2016 and finished in March 2017. The cohort ended follow-up on March 2018. Data analysis is currently underway.

Conclusions: Innovative and culturally sensitive strategies to improve access to HIV prevention and treatment services for transgender women are vital to curb the burden of HIV epidemic for this key population. Findings of this intervention will inform future policies and research, including evaluation of its efficacy in a randomized controlled trial.

Trial Registration: ClinicalTrials.gov NCT03757117; https://clinicaltrials.gov/ct2/show/NCT03757117 
International Registered Report Identifier (IRRID): DERR1-10.2196/14091

(JMIR Res Protoc 2019;8(6):e14091) doi: 10.2196/14091

\section{KEYWORDS}

transgender persons; culturally competent care; patient navigation; HIV; retention in care; health services; Peru

\section{Introduction}

Globally, transgender women (TW) are at a high risk for HIV infection, with a pooled $19.1 \%$ prevalence and a 48.8 -fold increased odds of HIV compared with the general adult population [1]. Public health strategies are urgently needed to improve global HIV disparities among TW, including intervention approaches that address those health needs prioritized by the community [2]. In Peru, TW are disproportionately burdened by the HIV epidemic, with HIV prevalence estimates ranging from $30 \%$ to close to $45 \%$ [3-5] compared with less than $1 \%$ in the general population [6]. About 22,500 TW live in Lima (personal communication by Segura et al, 2010), the national capital and regional center, which is home to $80 \%$ of Peru's HIV epidemic [7], making it a key site for HIV interventions in Latin America. Improving access to HIV prevention and treatment services for TW in Peru is vital to curb the burden of HIV epidemic for this key population [8].

Gender affirmation is defined as the process of being recognized in one's internal felt gender and sense of oneself as having a particular gender identity $[9,10]$. Access to gender affirmation has been conceptualized across multiple domains: social (eg, passing in one's desired gender role, acceptance and use of preferred pronouns or name, and wearing desired clothes associated with gender identity), medical (eg, hormone therapy or surgery), and legal (eg, legal name change, change of birth certificate sex or passport/ID reflecting gender identity) [11]. Not all types of affirmation are needed or desired by transgender individuals. Hormone therapy is the primary method by which many TW medically achieve gender affirmation [12], as some consider body modification an important step in aligning their outward physical gender presentation with their internal felt sense of their gender [10]. The implementation of gender-affirming care has been shown to improve psychological well-being among TW [11,13]. Furthermore, studies suggest that the integration of gender-affirmative care, including delivery of feminizing hormone therapy, may facilitate TW engagement in HIV care $[14,15]$. Integrating hormone therapy with HIV prevention and care may increase patient-provider trust, provide an opportunity for patients and providers to discuss what is known about drug-drug interactions between antiretroviral medications and hormones shown to impede HIV prevention and treatment uptake and adherence among TW, foster positive interactions, reduce barriers to obtaining needed services, and support ongoing engagement and retention in HIV care $[15,16]$.

Further evidence from Peru highlights lack of medical training and insufficient culturally competent clinical services to implement feminizing hormone therapy for TW [17]. As a result, gender affirmation procedures are usually performed outside the health system in informal peer-delivered systems [4]. In this setting, trained TW community members, as educators and/or peer navigators, could improve gender-affirming medical care and also be involved into and support HIV service delivery programs, as research demonstrated the effectiveness of peer navigation to engage and retain underserved populations living with HIV in stable primary medical care [18].

In recent years, the concept of an HIV treatment cascade has emerged as a way to identify gaps in the continuum of how well people living with HIV are engaged in medical care. It consists of 5 main steps, including diagnosis, linkage to care, retention in care, adherence to antiretroviral therapy, and viral suppression [19]. Similarly, an HIV prevention cascade model has been proposed to assist in the implementation and monitoring of HIV prevention programs by identifying gaps in the steps required for effective use of prevention methods, including motivation, access, and effective use in a priority population that would benefit from the prevention method [20].

The Féminas (the plural form of Fémina in Spanish, meaning Feminine in English) study was designed to assess the feasibility and acceptability of a service delivery model designed to improve the HIV treatment and prevention cascades among TW in Lima, Peru, by integrating HIV prevention and care services with gender-affirming transgender medical care supported by peer navigation. The study was grounded in an implementation science framework, which aimed to test and translate research to promote evidence-based practices for improving health and well-being [21,22]. Specific design considerations were given to elements that could be replicated by different institutions, including the Ministry of Health, nongovernmental organizations and community-based organizations (CBOs) providing HIV prevention and care for $\mathrm{TW}$, and/or researchers seeking to develop health interventions culturally tailored to the needs of TW. A mixed-methods formative research study was conducted to explore barriers and facilitators to implementing the proposed model of care. Perceived acceptability of the integrated care model was high among TW $(\mathrm{n}=48)$ and health care professionals $(n=19)$ alike. Barriers for implementation included stigma, lack of provider training or Peruvian guidelines regarding optimal TW care, and service delivery obstacles (eg, legal documents, spatial placement of clinics, and hours of operation). The hiring of TW staff was identified as a key facilitator for engagement in health care [17,23]. These findings informed that working in partnership with local TW and health care provider organizations is critical to overcoming existing barriers to successful implementation of an integrated HIV prevention and treatment services and gender-affirmative medical care model for TW in Peru. 


\section{Methods}

\section{Study Design}

Between October 1, 2016 and March 31, 2017, a 12-month, nonrandomized, single-arm cohort study was enrolled in Lima, Peru, to assess the feasibility and acceptability of integrating routine HIV prevention and treatment services with gender-affirming care (ie, feminizing hormone therapy) supported by TW community peer health navigators (Figure 1).

The study was led by Asociacion Civil Impacta Salud y Educacion (IMPACTA), a nongovernmental HIV research organization, in partnership with Epicentro, a CBO that provides low-cost HIV and sexually transmitted infection (STI) testing and care, community services, and hosts volunteer-driven community activities, which served as a research site for all study operations. The Fenway Institute at Fenway Health, a leading center of transgender clinical care, training, education, and research in Boston, Massachusetts, United States, served as a research partner. Fenway Health's informed consent model of transgender care and community-based transgender health research [24] were the basis for the Féminas intervention in Lima, Peru.

Figure 1. Schematic of gender-affirming health care and peer navigation to improve the HIV prevention and treatment cascades. ART: antiretroviral therapy; PrEP: pre-exposure prophylaxis; STI: sexually transmitted infection; TW transgender women.

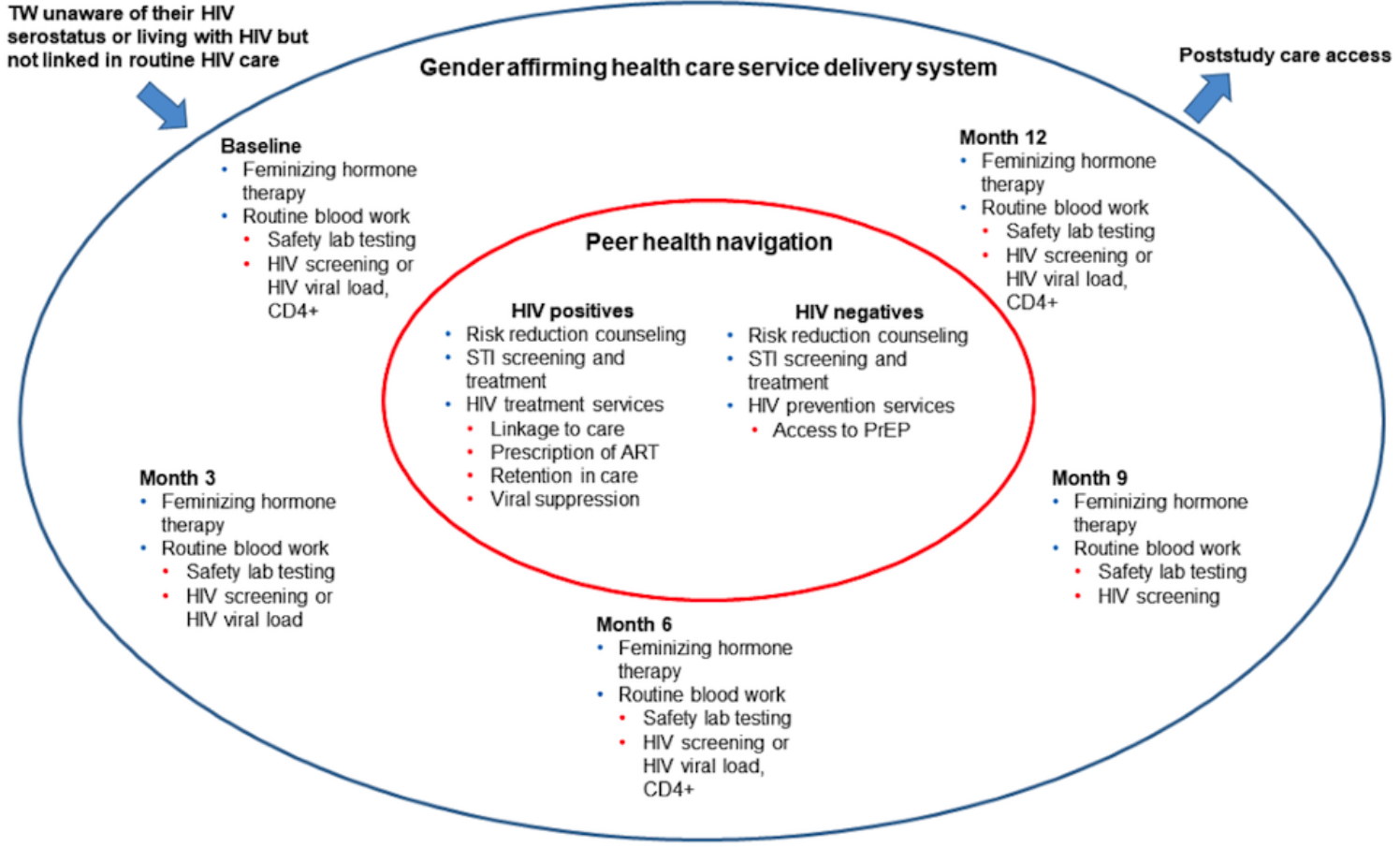

\section{Entry Criteria}

Adult individuals, aged 18 years or older, assigned a male sex at birth, who identified themselves as TW or on the trans-feminine continuum (eg, trans, travesti, transgender, or transsexual), regardless of initiation or completion of medical gender affirmation procedures, and who were unaware of their HIV serostatus or were living with HIV but not engaged in HIV treatment, were eligible to participate.

\section{Community Engagement and Education}

To enhance community engagement and for following principles of Good Participatory Practice to ensure ethical and scientific integrity [25,26], a Task Force composed of TW community representatives was convened for the study. The Task Force, acting as a community advisory board, informed the investigators on community issues, advised on study design, supported development of educational programs and campaigns, and facilitated collaborations with the study population. The Task Force also played a pivotal role in creating the Féminas house, as a separate stand-alone community facility and space for health care, support, and community programming placed at Epicentro. Community mobilization activities conducted at this setting were coordinated by a member of the TW community. Tailored annual community engagement and education plans were designed in advance of study implementation to include the following: (1) formative research for stakeholder identification and educational material validation; (2) community awareness activities; and (3) study communication, including development of educational materials, community consultations, and communication of study results.

\section{Training}

Formative research informed the development of training plans to educate study providers, peer health navigators, and community stakeholders on the hormone therapy intervention. TW community representatives and health care providers received medical education training in health care needs, services, and strategies including a gender-affirmative approach to transgender medical care, feminizing hormone therapy, managing HIV infection, and the peer health navigation to improve linkage and retention in care. 


\section{Recruitment}

Purposive sampling was used to recruit potential participants. Peer recruiters conducted outreach work by visiting TW-specific socialization venues, including discotheques, bars, erotic movie theaters, sex work areas, beauty parlors, volleyball courts, and others. In the field, recruiters approached their peers and asked for their verbal consent to receive information about the study design and criteria for participation. Flyers containing educational material and contact information were distributed after these informative meetings to refer potential participants to the research site for screening. This recruitment strategy was complemented by social media initiatives to promote study participation.

\section{Screening}

Counselors explained the study objectives to volunteers and obtained written informed consent to be screened for participation, HIV and STI testing, sample storage for future testing in ancillary studies, and contact for future studies. Participants underwent a computer-assisted self-interview (CASI) to assess demographics, gender identity, sexual orientation and role, sexual risk behavior, previous HIV testing and diagnosis, history of body enhancement procedures and hormone therapy use, life expectations, problems and barriers perceived because of being TW, HIV testing history, and prior engagement in care, if HIV positive. Counselors assisted participants in cases of computer unfamiliarity or literacy challenges. Physicians obtained a brief medical history and performed a targeted physical examination. A peripheral blood sample was obtained for assessment of HIV, syphilis, hepatitis $B$ virus (HBV) and hepatitis C virus (HCV) infection, as well as hematology and biochemistry laboratory tests. Participants underwent oropharyngeal and rectal swabbing and provided a urine sample for the diagnosis of Neisseria gonorrhoeae and Chlamydia trachomatis infection. An anal cytobrush was used to assess the presence of cytological abnormalities induced by human papillomavirus infection. Participants were asked to provide 2 sputum samples and undergo a chest $\mathrm{x}$-ray to rule out active tuberculosis. Volunteers were convened to return to the research site in 2 weeks for the provision of results and enrollment if they were eligible and agreed to participate (Table $1)$. 
Table 1. Study schedule of events.

\begin{tabular}{|c|c|c|c|c|c|c|c|c|c|c|c|c|c|c|}
\hline \multirow[t]{2}{*}{ Procedures } & \multirow[t]{2}{*}{ Screening } & \multicolumn{13}{|c|}{ Postentry evaluations (months) ${ }^{\mathrm{a}}$} \\
\hline & & 0 & 1 & 2 & 3 & 4 & 5 & 6 & 7 & 8 & 9 & 10 & 11 & 12 \\
\hline Informed consent & $\mathrm{X}^{\mathrm{b}}$ & $\mathrm{X}$ & $-^{c}$ & - & - & - & - & - & - & - & - & - & - & - \\
\hline Medical history & $\mathrm{X}$ & - & - & - & - & - & - & - & - & - & - & - & - & - \\
\hline Medication history & $\mathrm{X}$ & - & - & - & - & - & - & - & - & - & - & - & - & - \\
\hline Clinical assessment & $\mathrm{X}$ & - & $\mathrm{X}$ & - & $\mathrm{X}$ & - & - & $\mathrm{X}$ & - & - & $\mathrm{X}$ & - & - & $\mathrm{X}$ \\
\hline Complete physical exam & $\mathrm{X}$ & - & - & - & - & - & - & - & - & - & - & - & - & - \\
\hline Targeted physical exam & & - & $\mathrm{X}$ & - & $\mathrm{X}$ & - & - & $\mathrm{X}$ & - & - & $\mathrm{X}$ & - & - & $\mathrm{X}$ \\
\hline Computer-assisted self-interview & $X$ & - & - & - & $X$ & - & - & $\mathrm{X}$ & & - & $\mathrm{X}$ & - & - & $X$ \\
\hline Complete blood count & $\mathrm{X}$ & - & $\mathrm{X}$ & - & $\mathrm{X}$ & - & - & $\mathrm{X}$ & - & - & - & - & - & $\mathrm{X}$ \\
\hline Liver and renal function tests & $\mathrm{X}$ & - & $\mathrm{X}$ & - & $\mathrm{X}$ & - & - & $\mathrm{X}$ & - & - & - & - & - & $\mathrm{X}$ \\
\hline Fasting glucose and lipids & & $\mathrm{X}$ & - & - & - & - & - & $\mathrm{X}$ & - & - & - & - & - & $\mathrm{X}$ \\
\hline Estradiol and total testosterone & & $\mathrm{X}$ & - & - & $\mathrm{X}$ & - & - & $\mathrm{X}$ & - & - & - & - & - & $\mathrm{X}$ \\
\hline Chest $\mathrm{x}$ ray and sputum samples & $\mathrm{X}$ & - & - & - & - & - & - & - & - & - & - & - & - & 一 \\
\hline Risk reduction counseling, condoms, and lubricants & $X$ & $\mathrm{X}$ & - & - & $\mathrm{X}$ & - & - & $\mathrm{X}$ & - & - & $\mathrm{X}$ & - & - & $\mathrm{X}$ \\
\hline $\begin{array}{l}\text { Sampling for Neisseria gonorrhoeae and Chlamydia } \\
\text { trachomatis testing }\end{array}$ & $\mathrm{X}$ & - & - & - & - & - & - & - & - & - & - & - & - & - \\
\hline Sampling for anal cytological abnormalities & $X$ & - & - & - & - & - & - & - & - & - & - & - & - & - \\
\hline Syphilis serology & $X$ & - & - & - & $\mathrm{X}$ & - & - & $\mathrm{X}$ & - & - & $\mathrm{X}$ & - & - & $X$ \\
\hline Hepatitis B and hepatitis C serology & $X$ & - & - & - & - & - & - & - & - & - & - & - & - & - \\
\hline HIV serology & $\mathrm{X}$ & - & - & - & - & - & - & - & - & - & - & - & - & - \\
\hline Care of HIV negative & & - & - & - & - & - & - & - & - & - & - & - & - & - \\
\hline HIV serology & & - & - & - & $\mathrm{X}$ & - & - & $\mathrm{X}$ & - & - & $\mathrm{X}$ & - & - & $X$ \\
\hline Pre-exposure prophylaxis dispensation & & $\mathrm{X}$ & $\mathrm{X}$ & - & $\mathrm{X}$ & - & - & $\mathrm{X}$ & - & - & $\mathrm{X}$ & - & - & $\mathrm{X}$ \\
\hline Care of HIV positive & & - & - & - & - & - & - & - & - & - & - & - & - & - \\
\hline CD4+ cell count & & $\mathrm{X}$ & - & - & - & - & - & $\mathrm{X}$ & - & - & - & - & - & $\mathrm{X}$ \\
\hline HIV-1 RNA & & $\mathrm{X}$ & - & - & $\mathrm{X}$ & - & - & $\mathrm{X}$ & - & - & - & - & - & $X$ \\
\hline Antiretroviral treatment dispensation & & $\mathrm{X}$ & $\mathrm{X}$ & - & $\mathrm{X}$ & - & - & $\mathrm{X}$ & - & - & $\mathrm{X}$ & - & - & $\mathrm{X}$ \\
\hline Feminizing hormone therapy & & - & - & - & - & - & - & - & - & - & - & - & - & - \\
\hline Adherence counseling and education & & $X$ & $X$ & - & $\mathrm{X}$ & - & - & $\mathrm{X}$ & - & - & $\mathrm{X}$ & - & - & $\mathrm{X}$ \\
\hline Dispensation & & $X$ & $X$ & $X$ & $\mathrm{X}$ & $\mathrm{X}$ & $\mathrm{X}$ & $\mathrm{X}$ & $\mathrm{X}$ & $\mathrm{X}$ & $\mathrm{X}$ & $\mathrm{X}$ & $\mathrm{X}$ & $X$ \\
\hline Peer health navigation support & $X$ & $\mathrm{X}$ & $\mathrm{X}$ & $\mathrm{X}$ & $\mathrm{X}$ & $\mathrm{X}$ & $\mathrm{X}$ & $\mathrm{X}$ & $\mathrm{X}$ & $\mathrm{X}$ & $\mathrm{X}$ & $\mathrm{X}$ & $\mathrm{X}$ & $\mathrm{X}$ \\
\hline
\end{tabular}

${ }^{\text {a } V i s i t s ~ t o ~ o c c u r ~ e v e r y ~} 30$ days \pm 5 days.

${ }^{\mathrm{b}}$ The procedure is indicated at the specific study visit.

${ }^{\mathrm{c}}$ Not applicable.

\section{Enrollment}

Peer health navigators remained in contact with screened participants and facilitated their return to the research site for enrollment. At the site, a physician assessed eligibility, which included TW who resided in Lima and had normal hematology and biochemistry laboratory results. Individuals presenting with active tuberculosis; history of pancreatitis; severe or depending alcohol or drug consumption; severe medical comorbidity; reporting the use of immunosuppressive, nephrotoxic, or hepatotoxic therapy; or having any other health condition that in the opinion of the investigator would interfere with the evaluation of the study objectives were excluded. Volunteers received a detailed explanation of the risks and benefits of the medical intervention. Consenting participants underwent a CASI questionnaire, which included questions about personal and social network support for resilience to societal stigma and discrimination, hormone therapy expectations, and housing. A peripheral blood sample was obtained for assessment of baseline fasting glucose and lipids, estradiol, and total testosterone levels. All participants were prescribed and dispensed feminizing 
hormone therapy and invited to initiate HIV prevention and care as described in Table 1.

\section{Follow-Up}

Participants were asked to return to research site for study visits at months 1, 3, 6, 9, and 12, which included clinical and laboratory safety assessment, and hormone therapy adherence counseling and education following standard protocols [27]. At quarterly visits, participants underwent HIV (for those negatives) and syphilis testing, and answered a CASI questionnaire on gender identity and body image sexual risk behavior, substance use, attitudes toward HIV testing, personal and social network support, hormone therapy expectations, mental health, adherence to hormone therapy, and involvement in TW community building activities (Table 1). The occurrence of laboratory grade $\geq 2$ and clinical grade $\geq 3$ adverse events were monitored in all follow-up visits. All participants were instructed to report the occurrence of unintended effects of the study at any time. Peer health navigation facilitated retention in care and promoted adherence to study procedures, HIV prevention and care, and hormone therapy by visiting participants at home, work or socialization venues, or by contacting them by social media and phone.

\section{Regimen for Feminizing Hormone Therapy}

Hormone therapy followed Fenway Health's protocol providing medical care of transgender persons [27]. Hormones were dispensed on site on a monthly basis. Follow-up dosages were individualized in response to clinical efficacy or the occurrence of adverse events. Estradiol valerate was initiated at $2 \mathrm{mg}$ PO daily and increased to $4 \mathrm{mg}$ after 4 to 12 weeks. Antiandrogen therapy with spironolactone started at a dose of $50 \mathrm{mg}$ daily and indicated to be increased every 4 weeks to $200 \mathrm{mg}$ daily.

\section{HIV and Sexually Transmitted Infection Prevention and Care}

All participants received risk reduction counseling, condoms, and lubricants when tested for HIV and/or STI. Participants diagnosed with HIV infection were invited to be linked to HIV care at IMPACTA, placed 4 blocks away from the research site Epicentro, where local standard care was offered, including initiation of antiretroviral therapy (ART) and assessment of baseline and quarterly plasma HIV-1 RNA and CD4+ lymphocyte cell count monitoring [28]. HIV-negative participants were invited to initiate standard HIV pre-exposure prophylaxis (PrEP) with daily oral emtricitabine/tenofovir disoproxil fumarate [29], which was available at the research site at no cost. Participants diagnosed with STI received international standard treatment and those susceptible to HBV were referred for vaccination [30].

\section{Peer Health Navigation}

Socially well-connected community members representing the diverse subcultures of TW in the city and with preexisting knowledge of local HIV and related social resources were convened and provided with skills and confidence to help TW self-manage their health care needs with the ultimate goal to facilitate engagement in study procedures and retention in follow-up. Training in peer navigation followed Fenway Health's protocol for HIV system navigation [18]. Navigators were trained in several widely used frameworks, including the strengths-based perspective from social work practice, motivational interviewing, and stages of change. The strengths-based approach identifies, supports, and builds on patients' individual capacities, competencies, values, and hopes toward the goal of personal empowerment and resilience. Motivational interviewing is a theory-based, empirically valid approach that helps to change behaviors by examining and overcoming ambivalence that keeps many people from changing. Similar to motivational interviewing, the transtheoretical (stages of change) model provides a way to assess patients' readiness to adopt health-promoting behaviors. In addition to the initial 3-day training workshop, navigators received 4-hour monthly re-training sessions, in which barriers and facilitators experienced by navigating the system were shared and discussed [18].

\section{Laboratory Procedures}

HIV antibody screening was conducted on whole blood using Determine HIV-1/2 (Alere, Waltham, MA), a point-of-care third-generation HIV antibody test. Positive samples were sent for confirmatory testing by means of indirect immunofluorescence to the Peru National Institute of Health (NIH), unless a previous positive confirmatory result was identified in the Peru NIH database. Plasma HIV-1 RNA and CD4+ T-cell count assessments were also conducted at the Peru NIH. Antibodies to Treponema pallidum were detected using a rapid plasma reagin test (RPR Quicktest, Stanbio, Boerne, TX) and confirmed by a T. pallidum particle agglutination assay (DR0530, TPPA Test, Oxoid Limited, Basingstoke, UK). Both $\mathrm{HBV}$ (HBsAg, anti-HBc, and anti-HBs) and anti-HCV serologies were tested by means of chemoluminescent microparticle immunoassay (Architect, Abbott, Abbott Park, IL). N. gonorrhoeae and C. trachomatis infections were diagnosed by GeneXpert CT/NG (Cepheid, Sunnyvale, CA). Cytological slides were manually colored using standard Papanicolau staining. Sputum testing for tuberculosis used the Ziehl-Neelsen stain. Hematology (XS-1000i Sysmex America, Inc, Lincolnshire, IL), biochemistry (IFCC Vitros, Ortho Clinical Diagnostics, Raritan, NJ), and hormone (Cobas E-601, Roche Diagnostics, Indianapolis, IN) tests were assessed automatically. Unless previously specified, all tests other than hepatitis serology and hormone tests (at Anglolab laboratory) were conducted at the IMPACTA PERU Clinical Trials Unit Laboratory. All test results were provided to participants within a period of 14 days.

\section{Endpoints}

Endpoints at baseline were as follows: (1) proportion of participants who had ever been tested for HIV and (2) proportion of participants newly diagnosed as HIV positive. At the end of the intervention (12-month follow-up), the endpoints were (1) proportion of HIV-negative participants at baseline who were motivated, accessed, and effectively underwent quarterly HIV testing, used condoms or PrEP [20] and (2) proportion of HIV-positive participants at baseline who linked to and were retained in care, adhered to ART, and resulted in viral suppression [19]. Occurrence of study endpoints were assessed 
by an endpoint adjudication committee composed by the protocol team, led by the 3 study principal investigators.

\section{Data Management and Monitoring}

All participants' data were anonymized but not deidentified. All participants were identified with a unique alphanumeric code. The link between the participants' codes and identification was restricted to the study coordinator. It was stored in an electronic file and double password protected. Data were monitored for completeness, consistency, and accuracy, as well as for the occurrence of adverse events, in a biweekly basis by a protocol team led by the 3 study principal investigators.

\section{Statistical Considerations}

The target enrollment was $220 \mathrm{TW}$ for a total of 200 completers (>90\% retention during 12-months of follow-up) (Table 2). On the basis of these estimated percentages and assuming a moderate correlation across measurements $(\rho=.30)$ [31], the power to detect statistically significant differences across follow-up for all HIV cascade outcomes is greater than 0.80 . Quantitative analyses will be implemented in Stata SE 13.0 (Stata Corp, College Station, TX) software using 2-tailed tests of significance, with statistical significance at the alpha .05 level. A generalized estimating equation (GEE) approach will be used [31-33] with robust standard errors, which is an extension of regression analysis that properly accounts for repeated measures. Descriptive statistics will be obtained to summarize all variables. Bivariate tests ( $t$ tests/chi-square adjusted longitudinally using GEE) will examine changes in the proportion of TW across outcomes of interest, followed by multivariable longitudinal models adjusted for covariates (eg, age). GEE models use the number of observations as data points over time ( 5 visits $\times 200 \mathrm{TW}=1000$ observations). Multiple imputation [34,35] will be used assuming missingness is completely random.

Table 2. Projected sample sizes across HIV prevention and treatment cascade outcomes $(\mathrm{N}=200)$.

\begin{tabular}{|c|c|c|c|c|}
\hline Cascade stage & Baseline, n (\%) & 12-months, n (\%) & $\begin{array}{l}\text { Difference in } \\
\text { proportions }\end{array}$ & Outcomes \\
\hline $\begin{array}{l}\text { HIV test and risk reduction counseling in } \\
\text { past } 3 \text { months }\end{array}$ & $75(37.5)$ & $195(95.0)$ & 57.5 & $\begin{array}{l}\text { Increase in the proportion of TW who know their } \\
\text { HIV status }\end{array}$ \\
\hline HIV positive & $46(23.0)$ & $66(33.0)$ & 10.0 & Identify new HIV infections in TW \\
\hline Linked to care & $22(47.8)$ & $66(100.0)$ & 52.2 & $\begin{array}{l}\text { Increase in the proportion of HIV-positive TW } \\
\text { linked to care }\end{array}$ \\
\hline Retained in care & $9(40.9)$ & $60(90.9)$ & 50.0 & $\begin{array}{l}\text { Increase in the proportion of } \mathrm{HIV} \text {-positive } \mathrm{TW} \\
\text { retained in care and treatment }\end{array}$ \\
\hline Adhered to $\mathrm{ART}^{\mathrm{a}}$ & $11(50.0)$ & $60(90.9)$ & 40.9 & $\begin{array}{l}\text { Increase in the proportion of HIV-positive TW } \\
\text { prescribed ART }\end{array}$ \\
\hline Viral suppressed & $5(45.5)$ & $50(83.3)$ & 37.8 & $\begin{array}{l}\text { Increase in the proportion of HIV positive TW } \\
\text { who are virally suppressed }\end{array}$ \\
\hline HIV negative & $154(77.0)$ & $134(67.0)$ & 10.0 & Identify high-risk HIV-uninfected TW \\
\hline $\begin{array}{l}\text { Completed referrals to HIV prevention } \\
\text { services }\end{array}$ & $35(22.7)$ & $70(52.2)$ & 29.5 & $\begin{array}{l}\text { Link high-risk HIV-uninfected TW to HIV pre- } \\
\text { vention services, including access to pre-expo- } \\
\text { sure prophylaxis }\end{array}$ \\
\hline $\begin{array}{l}\mathrm{STI}^{\mathrm{b}} \text { screening, risk reduction counseling, } \\
\text { and treatment in past } 3 \text { months }\end{array}$ & $50(25.0)$ & $200(100.0)$ & 75.0 & $\begin{array}{l}\text { Increase in the proportion of TW screened and } \\
\text { treated for STIs }\end{array}$ \\
\hline
\end{tabular}

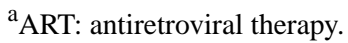

${ }^{\mathrm{b}} \mathrm{STI}$ : sexually transmitted infection.
}

Secondary analyses characterizing patterns of HIV virologic suppression over time will also be implemented. HIV cascade outcomes are also time to event data beyond the achievement of the dichotomous outcomes we propose. Therefore, data that allow us to capture the time at which an event of particular interest occurred (ie, virological suppression) will be collected. Patterns of change in biomarkers (ie, CD4+ cell count decrease) or the association between the primary endpoint and features of the longitudinal profiles are of interest. We will conduct joint modeling that enables longitudinal repeated biomarker measurements and survival processes to be modeled simultaneously while taking into account the association between them [36-38]. The random effects model for longitudinal data will be included in the survival model. Joint modeling provides less biased estimates and more efficient inferences than a 2-stage modeling approach [39-41]. We will use SAS 9.4 (SAS Institute Inc, Cary, NC) [42]. The joint modeling approach is well suited for our study because there is no control group (which is best suited for implementation science), and within-person change across time is being assessed.

\section{Protection of Human Subjects}

All participants were reimbursed approximately US \$13 in local currency (40 Soles) at each study visit. The study protocol and its amendments, informed consent forms, and recruitment and educational materials were approved by the IMPACTA's Institutional Bioethics Committee in compliance with all applicable Peruvian and US Federal regulations governing the protection of human subjects. All participants provided written 
informed consent for study screening and participation, receiving feminizing hormone therapy, HIV and STI testing, sample storage for future testing, and contact for future studies. The study protocol is registered at Peru National Institute of Health (Registro Nacional de Investigaciones en Salud EI00000345; dated on May 29, 2018) and Clinicaltrials.gov (Registration Number: NCT03757117; dated on November 28, 2018).

\section{Poststudy Care Access}

At the end of the intervention, all participants will be invited to continue receiving HIV and STI prevention and treatment at IMPACTA or referred to health care centers of the Peru Ministry of Health to receive it. It is expected that by time the study ends, feminizing hormone therapy will become available at public health care centers as part of the Ministry of Health policies to provide integrated HIV prevention and care to TW [43].

\section{Dissemination}

When intervention is near completion, the study team will prepare communication plans for disseminating and interpreting study results. We will host a preparatory activity of study results as a forum on the implications of the intervention targeting Ministry of Health representatives and the scientific and community stakeholders. In this forum, we will present a draft version Best Practices for dissemination of integrated TW health care services and ask audience for input that will be further incorporated. Thereafter, we will prepare the TW community for the disclosure of the results in a participant appreciation event.

\section{Results}

Patient recruitment started in October 2016 and final inclusion was March 2017. The cohort ended follow-up in March 2018. Data analysis is currently underway, and the first results are expected to be submitted for publication in June 2019.

\section{Discussion}

The Féminas study will investigate the feasibility and acceptability of an innovative service delivery model that integrates HIV prevention and treatment services with gender-affirming transgender medical care supported by peer navigation to improve the HIV prevention and care cascades among TW in Lima, Peru. To our knowledge, interventional research has not yet combined these 3 aspects to assess HIV outcomes across 12-months of prospective follow-up for TW primary medical care. The competent provision of feminizing hormones along with colocalized services targeting the HIV prevention and treatment cascades, supported by peer navigation, appears to be an attractive model for TW and an important aspect for future implementation of these services to address the HIV epidemic for TW.

For the success of the intervention, transgender community engagement is essential $[17,23]$. We promoted community mobilization through the implementation of community engagement and education plans, which were structured by members of the TW community in response to their health needs. Study procedures were implemented at a culturally competent $\mathrm{CBO}$ accustomed to regularly providing services for TW residents in Lima. The TW Task Force was particularly crucial in the beginning of the project to gather input on the study design and implementation and offer a vision of the model that would be maximally responsive to the needs of the population.

The coordinator of the Féminas house had a challenging role, given her proximity to the community and the many demands placed upon her in terms of the project and by her peers. It is vital that the TW community is represented in the staff, particularly in a leading role such as coordinator [44]. At the same time, caution is warranted so as not to tokenize or overburden this individual in her professional work as a transgender peer. The coordinator position must have supportive and ongoing supervision that is gender affirming with a person (or people) knowledgeable about TW communities and not necessarily within trans communities, preferably clinical supervision. This supervision needs to include ongoing assistance troubleshooting any number of challenging situations that can arise between the personal and professional aspects of project coordination and strategizing how best to manage insider trans women community politics with other peer leaders and organizations.

Peer navigation is vital for the Féminas model of care [18]. At every initial and subsequent point of contact and visit, participants have social, medical, legal, and other needs, which necessitate referrals and assistance. The peer health navigation takes a great deal of staff time and effort, much more than originally anticipated and budgeted given the many challenges and barriers to services facing TW in Lima in the broader context of social exclusion and economic marginalization. In HIV service models, peer health navigators generally have a caseload of 20 to $40 \mathrm{HIV}$-positive individuals, depending on the number of complex needs individuals they are supporting and availability and quality of health care services and systems $[45,46]$. For the Féminas model, a maximum of 25 TW peers per navigator would be ideal. Appropriate and realistic staffing and effort for peer health navigation is an important future consideration for the model. In addition, there are many types of and approaches to peer navigation; however, surprisingly few curricula exist to operationalize and skill-build TW peer health navigators. Compiling and disseminating a manualized curriculum to train on peer health navigation represents an important next step.

Our study has several limitations. First, as a pilot single-arm study without a standard-of-care arm, this interventional research cannot assess the effectiveness of the intervention. Nevertheless, this study will play a key role in the development or refinement of a potential future intervention that we anticipate could be tested for efficacy in a later trial [47]. Second, purposive sampling was used to convene potential participants to the study; therefore, study participants do not necessarily represent the TW community in Lima. Sampling may have been biased by the peer recruiters' knowledge of, and access to, different subgroups of TW. In addition, HIV-positive TW already in care were not included in the study. Thus, we will not be able to assess whether an integrated model of gender-affirming 
hormones and HIV care can improve HIV cascade outcomes for TW living with HIV and already receiving care.

The anticipated challenges inherent in studying at-risk populations include high participant attrition and low enrollment, as well as high rates of loss to follow-up. We have built a system robust against attrition through comprehensive collection of information on how to locate and contact participants, active tracking and engagement of participants between appointments using peer navigation, and reimbursement to minimize loss to follow-up. The study will gather information about retention efforts for TW in Lima, including diverse strategies to minimize attrition. It is anticipated that integration and colocalization of hormones and HIV prevention and care will support TW retention and facilitate engagement in the study [48].

Findings from this implementation science study will inform future policies and research, including evaluation of the efficacy of the Féminas intervention in a future randomized controlled trial.

\section{Acknowledgments}

This protocol study is funded by amfAR, The Foundation for AIDS Research (grant number: 109071-57-HGMM). The funders had no role in study design, data collection, management and analysis; decision to publish; or preparation of the manuscript. The authors would like to thank the community of TW in Lima, Peru, for their study participation; the Féminas Study Team including Thais Martinez, Francis Vara, Dania Calderon, Estephanie Peña, Vladimir Castañeda, Jhonatan Zamora, James Mallca, Eduardo Mattos, Aarón Trujillo, Sonia Sánchez, Misael Huertas (Epicentro), Carmela Ganoza, Lily Ganaha, Ricardo Alfaro, Clery Palacios, Rosa Blas, Javier Valencia, Eduardo Ruiz, Peter Brandes (Asociacion Civil Impacta Salud y Educacion), Sarah McLean, Aeysha Chaudry, Kathryn Snyder, and Alex Gonzales (The Fenway Institute) for their invaluable support in study implementation and operations; Mr Michael Cowing (amfAR) and Dr Susan Buchbinder (San Francisco Department of Public Health; amfAR Consultant) for their invaluable technical support advising study implementation and operations.

\section{Authors' Contributions}

JRL, KHM, JS, and SLR conceptualized and designed the study. JRL, KHM, AGP-B, LH, HS, JLC, JS, and SLR wrote the study protocol. JRL, KHM, AGP-B, JLC, and SLR drafted the manuscript. All authors read and approved the final version of the manuscript for publication.

\section{Conflicts of Interest}

None declared.

\section{Multimedia Appendix 1}

Study protocol funder's original peer-review reports.

[PDF File (Adobe PDF File), 42KB-Multimedia Appendix 1]

\section{References}

1. Baral SD, Poteat T, Strömdahl S, Wirtz AL, Guadamuz TE, Beyrer C. Worldwide burden of HIV in transgender women: a systematic review and meta-analysis. Lancet Infect Dis 2013 Mar;13(3):214-222. [doi: 10.1016/S1473-3099(12)70315-8] [Medline: 23260128]

2. Silva-Santisteban A, Eng S, de la Iglesia G, Falistocco C, Mazin R. HIV prevention among transgender women in Latin America: implementation, gaps and challenges. J Int AIDS Soc 2016 Jul;19(3 Suppl 2):20799 [FREE Full text] [doi: 10.7448/IAS.19.3.20799] [Medline: 27431470]

3. Sanchez J, Lama JR, Kusunoki L, Manrique H, Goicochea P, Lucchetti A, et al. HIV-1, sexually transmitted infections, and sexual behavior trends among men who have sex with men in Lima, Peru. J Acquir Immune Defic Syndr 2007 Apr 15;44(5):578-585. [doi: 10.1097/QAI.0b013e318033ff82] [Medline: 17279049]

4. Silva-Santisteban A, Raymond HF, Salazar X, Villayzan J, Leon S, McFarland W, et al. Understanding the HIV/AIDS epidemic in transgender women of Lima, Peru: results from a sero-epidemiologic study using respondent driven sampling. AIDS Behav 2012 May;16(4):872-881. [doi: 10.1007/s10461-011-0053-5] [Medline: 21983694]

5. Clark JL, Konda KA, Silva-Santisteban A, Peinado J, Lama JR, Kusunoki L, et al. Sampling methodologies for epidemiologic surveillance of men who have sex with men and transgender women in Latin America: an empiric comparison of convenience sampling, time space sampling, and respondent driven sampling. AIDS Behav 2014 Dec;18(12):2338-2348 [FREE Full text] [doi: 10.1007/s10461-013-0680-0] [Medline: 24362754]

6. García PJ, Holmes KK, Cárcamo CP, Garnett GP, Hughes JP, Campos PE, et al. Prevention of sexually transmitted infections in urban communities (Peru PREVEN): a multicomponent community-randomised controlled trial. The Lancet 2012 Mar;379(9821):1120-1128. [doi: 10.1016/S0140-6736(11)61846-1]

7. Ministry of Health of Peru. [National Center for Epidemiology, Prevention and Control of Diseases]. Epidemiological situation of HIV-AIDS in Peru URL: http://www.dge.gob.pe/portal/docs/vigilancia/vih/Boletin 2018/octubre.pdf [accessed 2019-01-17] 
8. Chow JY, Konda KA, Borquez A, Caballero P, Silva-Santisteban A, Klausner JD, et al. Peru's HIV care continuum among men who have sex with men and transgender women: opportunities to optimize treatment and prevention. Int J STD AIDS 2016 Dec;27(12):1039-1048 [FREE Full text] [doi: 10.1177/0956462416645727] [Medline: 27099168]

9. Sevelius JM. Gender affirmation: a framework for conceptualizing risk behavior among transgender women of color. Sex Roles 2013 Jun 01;68(11-12):675-689 [FREE Full text] [doi: 10.1007/s11199-012-0216-5] [Medline: 23729971]

10. Bockting W, Coleman E, Deutsch MB, Guillamon A, Meyer I, Meyer W, et al. Adult development and quality of life of transgender and gender nonconforming people. Curr Opin Endocrinol Diabetes Obes 2016 Apr;23(2):188-197 [FREE Full text] [doi: 10.1097/MED.0000000000000232] [Medline: 26835800]

11. Glynn T, Gamarel K, Kahler C, Iwamoto M, Operario D, Nemoto T. The role of gender affirmation in psychological well-being among transgender women. Psychol Sex Orientat Gend Divers 2016 Sep;3(3):336-344 [FREE Full text] [doi: 10.1037/sgd0000171] [Medline: 27747257]

12. Hembree WC, Cohen-Kettenis PT, Gooren L, Hannema SE, Meyer WJ, Murad MH, et al. Endocrine treatment of gender-dysphoric/gender-incongruent persons: an endocrine society clinical practice guideline. J Clin Endocrinol Metab 2017 Dec 01;102(11):3869-3903. [doi: 10.1210/jc.2017-01658] [Medline: 28945902]

13. White Hughto JM, Reisner SL. A systematic review of the effects of hormone therapy on psychological functioning and quality of life in transgender individuals. Transgend Health 2016 Jan;1(1):21-31 [FREE Full text] [doi:

10.1089/trgh.2015.0008] [Medline: 27595141]

14. Sevelius JM, Patouhas E, Keatley JG, Johnson MO. Barriers and facilitators to engagement and retention in care among transgender women living with human immunodeficiency virus. Ann Behav Med 2014 Feb;47(1):5-16 [FREE Full text] [doi: 10.1007/s12160-013-9565-8] [Medline: 24317955]

15. Sevelius JM, Saberi P, Johnson MO. Correlates of antiretroviral adherence and viral load among transgender women living with HIV. AIDS Care 2014;26(8):976-982 [FREE Full text] [doi: 10.1080/09540121.2014.896451] [Medline: 24646419]

16. Braun HM, Candelario J, Hanlon CL, Segura ER, Clark JL, Currier JS, et al. Transgender women living with HIV frequently take antiretroviral therapy and/or feminizing hormone therapy differently than prescribed due to drug-drug interaction concerns. LGBT Health 2017 Dec;4(5):371-375 [FREE Full text] [doi: 10.1089/lgbt.2017.0057] [Medline: 28876170]

17. Reisner SL, Perez-Brumer AG, McLean SA, Lama JR, Silva-Santisteban A, Huerta L, et al. Perceived barriers and facilitators to integrating HIV prevention and treatment with cross- sex hormone therapy for transgender women in Lima, Peru. AIDS Behav 2017 Dec;21(12):3299-3311 [FREE Full text] [doi: 10.1007/s10461-017-1768-8] [Medline: 28421354]

18. Bradford J, Coleman S, Cunningham W. HIV system navigation: an emerging model to improve HIV care access. AIDS Patient Care STDS 2007;21 Suppl 1:S49-S58. [doi: 10.1089/apc.2007.9987] [Medline: 17563290]

19. Kay ES, Batey DS, Mugavero MJ. The HIV treatment cascade and care continuum: updates, goals, and recommendations for the future. AIDS Res Ther 2016;13:35 [FREE Full text] [doi: 10.1186/s12981-016-0120-0] [Medline: 27826353]

20. Schaefer R, Gregson S, Fearon E, Hensen B, Hallett T, Hargreaves J. HIV prevention cascades: a unifying framework to replicate the successes of treatment cascades. Lancet HIV 2019 Jan;6(1):e60-e66. [doi: 10.1016/S2352-3018(18)30327-8]

21. Bauer MS, Damschroder L, Hagedorn H, Smith J, Kilbourne AM. An introduction to implementation science for the non-specialist. BMC Psychol 2015 Sep 16;3:32 [FREE Full text] [doi: 10.1186/s40359-015-0089-9] [Medline: 26376626]

22. Odeny TA, Padian N, Doherty MC, Baral S, Beyrer C, Ford N, et al. Definitions of implementation science in HIV/AIDS. Lancet HIV 2015 May;2(5):e178-e180. [doi: 10.1016/S2352-3018(15)00061-2] [Medline: 26423000]

23. Perez-Brumer AG, Reisner SL, McLean SA, Silva-Santisteban A, Huerta L, Mayer KH, et al. Leveraging social capital: multilevel stigma, associated HIV vulnerabilities, and social resilience strategies among transgender women in Lima, Peru. J Int AIDS Soc 2017 Dec 28;20(1):21462 [FREE Full text] [doi: 10.7448/IAS.20.1.21462] [Medline: 28362064]

24. Reisner SL, Bradford J, Hopwood R, Gonzalez A, Makadon H, Todisco D, et al. Comprehensive transgender healthcare: the gender affirming clinical and public health model of Fenway Health. J Urban Health 2015 Jun;92(3):584-592 [FREE Full text] [doi: 10.1007/s11524-015-9947-2] [Medline: 25779756]

25. UNAIDS. Good participatory practice: Guidelines for biomedical HIV prevention trials (2011). Geneva, Switzerland: Joint United Nations Programme on HIV/AIDS; 2011 Jun 29. URL: https://www.unaids.org/sites/default/files/media_asset/ JC1853 GPP Guidelines 2011 en 0.pdf [accessed 2019-01-07]

26. Leung M, Yen I, Minkler M. Community based participatory research: a promising approach for increasing epidemiology's relevance in the 21st century. Int J Epidemiol 2004 Jun;33(3):499-506. [doi: 10.1093/ije/dyh010] [Medline: 15155709]

27. The Fenway Institute. Fenway Health. Boston, MA; 2015. The medical care of transgender persons URL: https://www. lgbthealtheducation.org/wp-content/uploads/COM-2245-The-Medical-Care-of-Transgender-Persons.pdf [accessed 2019-01-17]

28. [Ministry of Health of Peru]. Digemid - Minsa. Lima, Peru: [Ministry of Health of Peru]; 2014. [Technical standard of health of integral care of the adult with infection with the virus of human immunodeficiency (HIV)] URL: http://www. digemid.minsa.gob.pe/UpLoad/UpLoaded/PDF/Normatividad/2014/RM_962-2014.pdf [accessed 2019-01-07]

29. World Health Organization. Consolidated Guidelines on the Use of Antiretroviral Drugs for Treating and Preventing HIV Infection. Geneva, Switzerland: World Health Organization; 2016. URL: https://apps.who.int/iris/bitstream/handle/10665/ 208825/9789241549684_eng.pdf?sequence=1 [accessed 2019-01-07] 
30. Workowski K, Bolan G, Centers for Disease Control and Prevention. Sexually transmitted diseases treatment guidelines, 2015. MMWR Recomm Rep 2015 Jun 05;64(RR-03):1-137 [FREE Full text] [Medline: 26042815]

31. Fitzmaurice GM, Laird NM, Ware JH. Applied Longitudinal Analysis. Hoboken: Wiley; 2011.

32. Zeger S, Liang K, Albert P. Models for longitudinal data: a generalized estimating equation approach. Biometrics 1988 Dec;44(4):1049-1060. [Medline: 3233245]

33. Liang K, Zeger SL. Longitudinal data analysis using generalized linear models. Biometrika 1986;73(1):13-22. [doi: 10.1093/biomet/73.1.13]

34. Lee KJ, Carlin JB. Multiple imputation for missing data: fully conditional specification versus multivariate normal imputation. Am J Epidemiol 2010 Mar 01;171(5):624-632. [doi: 10.1093/aje/kwp425] [Medline: 20106935]

35. van Buuren S. Multiple imputation of discrete and continuous data by fully conditional specification. Stat Methods Med Res 2007 Jun;16(3):219-242. [doi: 10.1177/0962280206074463] [Medline: 17621469]

36. Henderson R, Diggle P, Dobson A. Joint modelling of longitudinal measurements and event time data. Biostatistics 2000 Dec;1(4):465-480. [doi: 10.1093/biostatistics/1.4.465] [Medline: 12933568]

37. Wang Y, Taylor J. Jointly modeling longitudinal and event time data with application to acquired immunodeficiency syndrome. J Am Statistical Assoc 2014 Sep;96(455):895-905. [doi: 10.1198/016214501753208591]

38. Tsiatis A, Davidian M. Joint modeling of longitudinal and time-to-event data: An overview. Statistica Sinica 2004 Jul;14(3):809-834 [FREE Full text]

39. Albert PS, Shih JH. On estimating the relationship between longitudinal measurements and time-to-event data using a simple two-stage procedure. Biometrics 2010 Sep;66(3):983-987. [doi: 10.1111/j.1541-0420.2009.01324_1.x] [Medline: 20849547]

40. Tsiatis AA, DeGruttola V, Wulfsohn MS. Modeling the relationship of survival to longitudinal data measured with error. Applications to survival and CD4 counts in patients with AIDS. J Am Stat Assoc 1995 Mar;90(429):27-37. [doi: $10.2307 / 2291126]$

41. Wulfsohn M, Tsiatis A. A joint model for survival and longitudinal data measured with error. Biometrics 1997 Mar;53(1):330-339. [Medline: 9147598]

42. Rizopoulos D. JM: An R package for the joint modelling of longitudinal and time-to-event data. J Statistical Software 2010;35(9):1-33. [doi: 10.18637/jss.v035.i09]

43. [Ministry of Health of Peru]. [Ministry of Health of Peru]. Lima, Peru: [Ministry of Health of Peru]; 2016. [Health Technical Standard $N^{\circ}$ 126-MINSA / 2016 / DGIESP. Technical standard of health of comprehensive care of the female transgender population for the prevention and control of sexually transmitted infections and HIV / AIDS] URL: ftp://ftp2.minsa.gob.pe/ normaslegales/2016/RM-_N_980-2016-MINSA.pdf [accessed 2019-01-07]

44. National LGBT Health Education Center. Boston, MA; 2018. Creating a Transgender Health Program at Your Health Center: From Planning to Implementation URL: https://www.lgbthealtheducation.org/wp-content/uploads/2018/10/ Creating-a-Transgender-Health-Program.pdf [accessed 2019-05-24]

45. United States Agency for International Development. Washington, DC: FHI 360/LINKAGES; 2017. Peer navigation for key populations URL: https://tinyurl.com/y6teetjq [accessed 2019-05-26]

46. TargetHIV. Rockville, MD; 2018. The SPNS Transgender Women of Color Initiative Interventions Manual URL: https:/ /www.targethiv.org/sites/default/files/file-upload/resources/SPNS TWOCInterventionsManual 2018.pdf [accessed 2019-05-25]

47. Leon AC, Davis LL, Kraemer HC. The role and interpretation of pilot studies in clinical research. J Psychiatr Res 2011 May;45(5):626-629 [FREE Full text] [doi: 10.1016/j.jpsychires.2010.10.008] [Medline: 21035130]

48. Reisner SL, Radix A, Deutsch MB. Integrated and gender-affirming transgender clinical care and research. J Acquir Immune Defic Syndr 2016 Dec 15;72(Suppl 3):S235-S242 [FREE Full text] [doi: 10.1097/QAI.0000000000001088] [Medline: 27429189]

\author{
Abbreviations \\ ART: antiretroviral therapy \\ CASI: computer-assisted self-interview \\ CBO: community-based organization \\ GEE: generalized estimating equation \\ HBV: hepatitis B virus \\ HCV: hepatitis $C$ virus \\ IMPACTA: Asociacion Civil Impacta Salud y Educacion \\ NIH: National Institute of Health \\ PrEP: pre-exposure prophylaxis \\ STI: sexually transmitted infection \\ TW: transgender women
}


Edited by $G$ Eysenbach; submitted 21.03.19; peer-reviewed by T Poteat, A Eaton, W Tang; comments to author 27.04.19; revised version received 29.05.19; accepted 29.05.19; published 27.06.19

Please cite as:

Lama JR, Mayer KH, Perez-Brumer AG, Huerta L, Sanchez H, Clark JL, Sanchez J, Reisner SL

Integration of Gender-Affirming Primary Care and Peer Navigation With HIV Prevention and Treatment Services to Improve the Health of Transgender Women: Protocol for a Prospective Longitudinal Cohort Study

JMIR Res Protoc 2019;8(6):e14091

URL: http://www.researchprotocols.org/2019/6/e14091/

doi: $\underline{10.2196 / 14091}$

PMID: $\underline{31250829}$

(CJavier R Lama, Kenneth H Mayer, Amaya G Perez-Brumer, Leyla Huerta, Hugo Sanchez, Jesse L Clark, Jorge Sanchez, Sari L Reisner. Originally published in JMIR Research Protocols (http://www.researchprotocols.org), 27.06.2019. This is an open-access article distributed under the terms of the Creative Commons Attribution License (https://creativecommons.org/licenses/by/4.0/), which permits unrestricted use, distribution, and reproduction in any medium, provided the original work, first published in JMIR Research Protocols, is properly cited. The complete bibliographic information, a link to the original publication on http://www.researchprotocols.org, as well as this copyright and license information must be included. 